\title{
Erratum to: Measurement and Modeling of Hydrogen Environment-Assisted Cracking in Monel K-500
}

\author{
RICHARD P. GANGLOFF, HUNG M. HA, JAMES T. BURNS, and JOHN R. SCULLY
}

DOI: $10.1007 / \mathrm{s} 11661-014-2454-3$

(C) The Minerals, Metals \& Materials Society and ASM International 2014

\section{Erratum to: METALLURGICAL AND MATERIALS TRANSACTIONS A, VOLUME 45A, AUGUST 2014, pp. 3814-3834 DOI: $10.1007 / \mathrm{s} 11661-014-2324-\mathrm{z}$}

IN the original article the vertical axes of Figures 17 and 18 are labeled incorrectly. Following are the corrected figures:

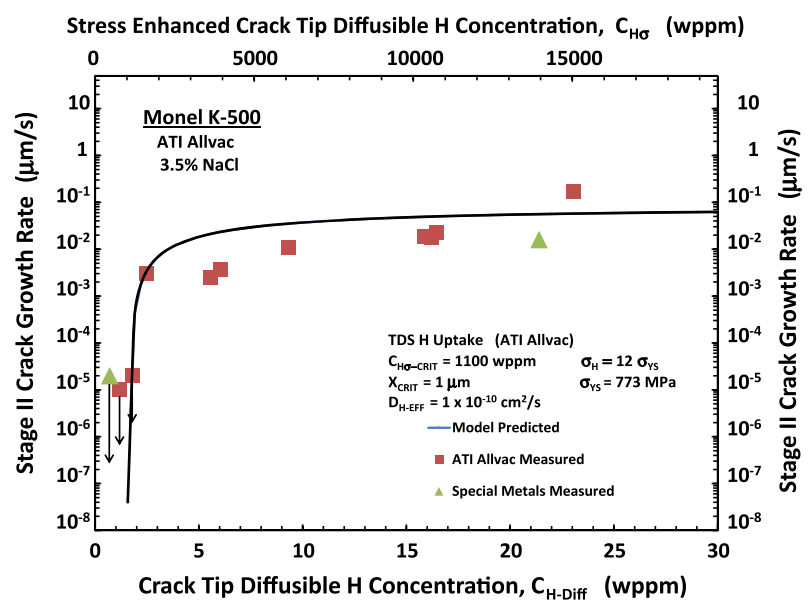

Fig. 17-(Color online) Model predicted (Eq. [2]) and measured Stage II crack growth rate (at elastic $K=50 \mathrm{MPa} \sqrt{\mathrm{m}}$, Table III; Fig. 9) vs crack tip $C_{\mathrm{H} \text {-Diff }}$ (bottom axis) and stress enhanced $C_{\mathrm{H} \sigma}$ (top axis) for aged Monel K-500 (ATI Allvac, $\mathbf{\square}$; Table I) stressed in 3.5 pet $\mathrm{NaCl}$ at $E_{\mathrm{A}}$ between -1100 and $-700 \mathrm{mV}_{\mathrm{SCE}}$. The $\sigma_{\mathrm{H}} / \sigma_{\mathrm{YS}}$ is 12.0 in Eq. [3]. Measured $\mathrm{d} a / \mathrm{d} t_{\mathrm{II}}$ are included for a Special Metals lot of Monel K-500 ( $\boldsymbol{\Delta})$ using the corresponding $\mathrm{H}$ uptake law (Footnotes $*$ and $* *$ ).

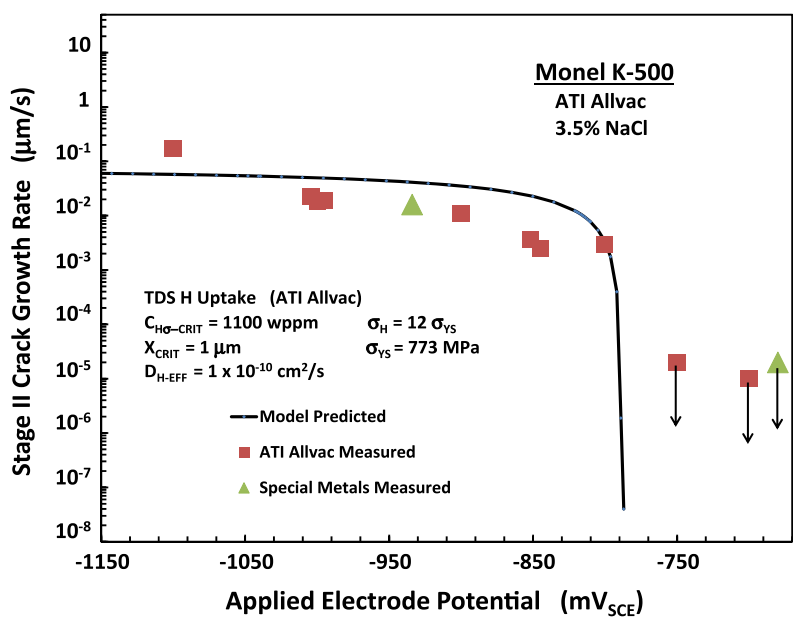

Fig. 18-(Color online) Model predicted (Eq. [2]) and measured Stage II crack growth rate (at elastic $K=50 \mathrm{MPa} \sqrt{\mathrm{m}}$, Table III; Fig. 9) $v s$ applied cathodic potential for aged Monel K-500 (ATI Allvac, $\mathbf{\square}$; Table I) stressed in 3.5 pct NaCl. The $\sigma_{\mathrm{H}} / \sigma_{\mathrm{YS}}$ equals 12.0 in Eq. [3]. Measured $\mathrm{d} a / \mathrm{d} t_{\mathrm{II}}$ values are included for a Special Metals lot of Monel K-500 (Footnote *, $\mathbf{\Delta}$ ).
RICHARD P. GANGLOFF and JOHN R. SCULLY, Professors, and JAMES T. BURNS, Research Assistant Professor, are with the Department of Materials Science and Engineering, Center for Electrochemical Science and Engineering, University of Virginia, Charlottesville, VA 22904. Contact e-mail: rpg7y@ Virginia.edu. HUNG M. HA, formerly Research Scientist with the Department of Materials Science and Engineering, Center for Electrochemical Science and Engineering, University of Virginia, is now Post-Doctoral Research Fellow with the Department of Materials Engineering, University of British Columbia, Vancouver, BC V6T 1Z4, Canada.

The online version of the original article can be found under doi: 10.1007/s11661-014-2324-z.

Article published online July 4, 2014 